\title{
Condom use among males (15-49 years) in Lower Egypt: knowledge, attitudes and patterns of use
}

I.A. Kabbash, ${ }^{1}$ N.M. El-Sayed, ${ }^{2}$ A.N. Al-Nawawy, ${ }^{3}$ I.K. Shady ${ }^{4}$ and M.S. Abou Zeid ${ }^{1}$

$$
\begin{aligned}
& \text { استخدام العازل للدى الذكور (15 - } 49 \text { عاماً) في صعيد مصر: المعارف والمو اقف وأنفاط الاستخدام }
\end{aligned}
$$

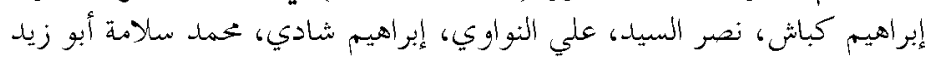

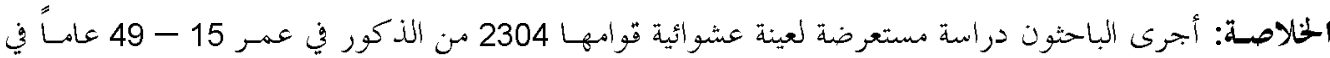

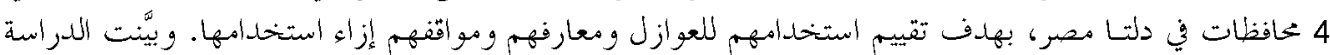

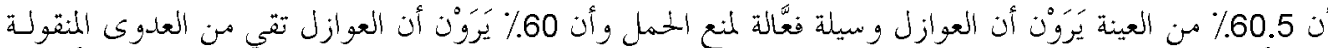

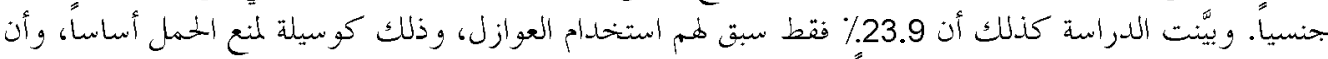

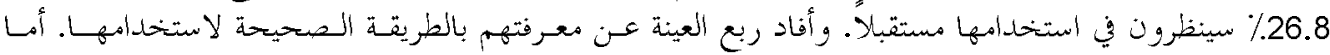

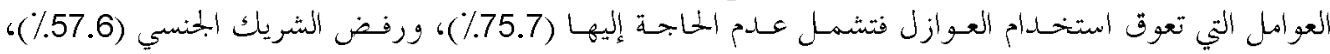

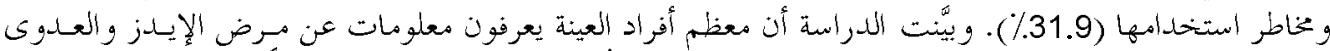

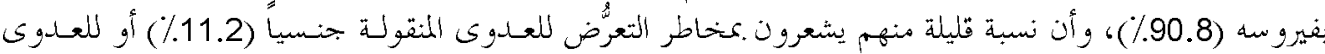$$
\text { بفيروس الإيدز (10.3\%). }
$$

ABSTRACT We conducted a cross-sectional study on a randomly selected sample of 2304 males aged 15-49 years from 4 governorates in Lower Egypt to assess their condom use and knowledge and attitudes towards condom use. Condoms were considered an effective method of contraception and prevention of transmission of sexually transmitted infections (STIs) by $60.5 \%$ and $60.0 \%$ respectively. Only $23.9 \%$ had ever used condoms, mainly for contraception, but $26.8 \%$ would consider using them in the future. A quarter reported knowing how to use condoms properly. Obstacles to condom use included perceived lack of need $(75.7 \%)$, rejection by partner $(57.6 \%)$ and hazards of condoms $(31.9 \%)$. The majority knew about HIVIAIDS (90.8\%) but a few felt at risk of STIs $(11.2 \%)$ or HIV infection (10.3\%).

L'usage du préservatif dans la population masculine (15-49 ans) de Basse-Égypte : connaissances, attitudes et profil des utilisateurs

RÉSUMÉ Nous avons mené une étude transversale sur un échantillon randomisé de 2304 sujets de sexe masculin, âgés de 15 à 49 ans et originaires de 4 gouvernorats de Basse Égypte, dans le but d'évaluer l'utilisation du préservatif masculin et les connaissances et attitudes à l'égard de ce dernier au sein de cette population. Le préservatif masculin est jugé efficace comme méthode contraceptive ou comme moyen de prévention contre les infections sexuellement transmissibles (IST) respectivement par $60,5 \%$ et $60,0 \%$ de l'échantillon. Seuls $23,9 \%$ des participants avaient déjà utilisé un préservatif, principalement à des fins contraceptives, mais $26,8 \%$ en envisageaient l'utilisation dans l'avenir. Vingt-cinq pour cent $(25 \%)$ des enquêtés déclaraient en connaître parfaitement le mode d'emploi. Les principaux obstacles à l'utilisation des préservatifs étaient la méconception de la nécessité $(75,7 \%)$, le rejet de la part du/de la partenaire $(57,6 \%)$ et les risques propres au préservatif (31,9\%). La majorité des enquêtés $(90,8 \%)$ était informée de l'existence du VIH/sida, mais seul un petit nombre admettait le risque de contamination par IST $(11,2 \%)$ ou le VIH (10,3\%).

${ }^{1}$ Department of Public Health, Social \& Preventive Medicine, University of Tanta, Tanta, Egypt (Correspondence to I.A. Kabbash: kabbash-ia@maktoob.com; iakabbash@hotmail.com).

${ }^{2}$ Primary Health Care, Preventive Medicine and Family Planning, Ministry of Health and Population, Cairo, Egypt. ${ }^{3}$ Department of Public Health and Community Medicine, Al-Azhar University (Damietta Branch), Damietta, Egypt.

${ }^{4}$ Department of Public Health, University of Mansoura, Mansoura, Egypt.

المجلة الصحية لشرق المتو سط، منظمة الصحة العالمية، المجلد الثالث عشر، العدد ج، V... 


\section{Introduction}

Men play a powerful role in reproductive decisions. Their actions can have unhealthy and even dangerous results. Men's participation is a promising strategy for addressing some of the world's pressing reproductive health problems. With HIV infection now spreading faster among women than among men, the AIDS epidemic has focused attention on the health consequences of men's sexual behaviour. At the same time surveys, mostly in Africa, have found that a considerable per cent of men (about $70 \%$ in some countries) favour and are concerned about family planning. Such findings suggest that men's reproductive health behaviour is ready to change [1]

Since the 1930s, latex condoms have been available to prevent both pregnancy and sexually transmitted disease, but in most parts of the world they have never been widely used [2]. Estimated pregnancy rates during perfect use of condoms is $3 \%$ at 12 months [3]. Numerous studies have been conducted on the risk of sexually transmitted infections (STIs) in condom users. Virtually all clinical and epidemiological studies have found substantial reductions in the risk of disease among condom users [4,5]. A multi-country European collaborative study enrolled 378 seronegative regular partners of HIV-infected men or women. About one-half of the couples used condoms at every intercourse, and no seroconversions occurred among these couples. About 10\% of the couples who used condoms inconsistently or not at all seroconverted with an incidence rate of $4.8 \%$ [6].

In Egypt, results of the 2003 Demographic and Health Survey showed that male methods of contraception are still less widely recognized than female methods [7]. In another study, it was found that $87 \%$ of Egyptian men were agreeable to using fam- ily planning. However, few were using a condom although more than $18 \%$ of married men surveyed reported having used a male method of contraception in the past including condoms [8]. Another study on the male role in reproductive health in Egypt showed that $64.7 \%$ of husbands did not wish to use male contraceptives including condoms [9]. A study in Pakistan, a country in the same region, showed low knowledge levels regarding the appropriate use and efficacy of condoms even among contraceptive users [10].

While perceived unreliability is often a problem, many other issues present greater barriers to overall acceptability of condoms. Many people do not believe they are at risk of STIs/AIDS. Others do not like the feeling of condoms or worry about their partner's reactions to suggesting condom use. Some are embarrassed by the buying and using of condoms or lack the skills to add their use to sexual activity [11].

In the era of HIV/AIDS, it is essential to study the pattern of condom use which is now not only important for family planning and reducing fertility indices but is also a live saver by preventing HIV infection.

This study aimed to study:

- the pattern of condom use among adult Egyptian males in Lower Egypt;

- the pattern of risky behaviour of Egyptian adult males necessitating condom use as a protective measure;

- the knowledge and attitudes of Egyptian adult males towards condom use and barriers to use.

\section{Methods}

\section{Study setting and subjects}

This was a cross-sectional study conducted during 2004 in 4 governorates randomly 
selected from the 13 governorates of lower Egypt. They were Gharbia, Damietta, Dakahlia and Menoufiya. Two randomly selected localities in each governorate (1 urban and 1 rural) were selected for data collection. The sampling frame for urban localities was based on the list of cities in each Governorate from which 1 city was chosen randomly. For the rural locality, a list of related villages to the chosen city was obtained from which 1 village was chosen randomly.

The target population of this study was adult males aged 15-49 years representing a sexually active group of the population. They were chosen from different educational levels and occupational groups; industrial workers, taxi and minibus drivers, university and secondary school students and government employees.

\section{Sample size}

Gharbia governorate, with a population of 3735700 , lies in the centre of the Nile Delta. Damietta governorate, with a population of 1005 243, lies on the northern coast. In Gharbia governorate, the population of males aged 15-49 years was 997859 while that of Damietta was 270 198. The estimated sample size in these 2 governorates was 1270 individuals (1000 in Gharbia and 270 in Damietta).

Dakahlia governorate is located in the east of the Nile Delta and has a population of 4825882 . Menoufiya is located in the south of the Nile Delta and has a population of 3058362 . The population of males aged 15-49 years in the 2 governorates was estimated to be 2275 493. The sample size represented $1 / 1000$ of the target population based on the CAPMAS census 1996 and estimated increase by end of 2003 [12]. Thus the total sample size in this study was 2304.

The sample size was drawn proportionally from the different study groups accord- ing to expected percentages of each in the community as estimated by the researchers because exact figures were not available.

\section{Sampling technique}

Random sample selection was done from strata representing different educations and occupations. The identified strata included: government employees, taxi and minibus drivers, industrial workers and university and secondary-school students.

Full lists of the available places of gathering of the target population of each stratum were obtained from the Governorate office and multiple places were chosen randomly. The total population of the chosen places were divided into clusters and 1 or 2 clusters were randomly chosen from each place to reach the required sample size. Clustering was based on the circumstances of each place; number of offices in governmental premises, different student sections in the faculties, workplace divisions. Drivers were all taken from the station of the chosen locality which was always one station for internal and another for external transportation (between governorates). Refusal rate to participate ranged between 2\% (among students) and 7\% (among drivers).

\section{Data collection}

A pre-designed questionnaire sheet (available on request from the corresponding author) was used for data collection. This questionnaire included the following data:

- Sociodemographic data (name not included)

- Perception of condoms as a method of protection against STIs and as a contraceptive method

- Pattern of condom use and barriers to use

- Practice of risky behaviours necessitating condom use as a protective measure against STIs.

المجلة الصحية لشرق المتوسط، منظمة الصحة العالمية، المجلد الثالث عشر، العدد Y، V... 
Content validity of the questionnaire was tested by 3 experts. A pilot study including 30 individuals, not included in the study sample, was performed to ensure the suitability of the questionnaire for data collection relevant to the study design and objectives. Results of the pilot study showed that direct enquiry about sexual behaviour was not acceptable to respondents. Therefore, the questions related to personal sexual activity were replaced by questions enquiring about friends with extramarital relations. This was found to be more acceptable and allowed projection of the prevalence of unsafe sexual relations in the studied community. Test-retest reliability was conducted to ensure intra-rater reliability. Inter-rater bias was not likely because the questionnaire was designed to be self-administered. Only those who could hardly read were helped in completing the questionnaire by the interviewers (about $5 \%-7 \%$ depending on the locality).

Data collection was done through direct interviewing by members of the research team who were trained on communication interviewing skills by senior experts in a 2-day workshop before starting data collection activities. Group interviewing was arranged with the study subjects before distribution of the study questionnaire to explain the importance of proper and complete filling of the questionnaire. Only fully completed sheets of those aged $15-49$ years were included in the study $(6 \%-7 \%$ were excluded of the total distributed).

\section{Data management and statistical analysis}

The collected data were organized and statistically analysed using SPSS, version 12 . The number and per cent distribution were calculated and the chi-squared test was used for statistical analysis. The 5\% level of significance was used for interpretation of the chi-squared results.

\section{Results}

Table 1 shows the characteristics of the 4 occupation groups. The study included 2304 males aged 15-49 years. These comprised 590 industrial workers (25.6\%), 382 drivers (16.6\%), 627 government employees $(27.2 \%)$ and 705 students $(30.6 \%)$. The majority of industrial workers and drivers had received primary and secondary education $(98.0 \%$ and $95.0 \%$ respectively) while $45.1 \%$ of government employees had received a higher education. Regarding students, $12.9 \%$ were secondary-school students while $87.1 \%$ were university students. Of the entire sample, $44.1 \%$ were urban residents and $42.2 \%$ were unmarried. The majority of industrial workers, drivers and employees were married $(79.0 \%, 67.8 \%$ and $84.1 \%$ respectively) while the majority of students were single $(98.2 \%)$.

Table 2 presents the knowledge and attitude of the sample towards condom use. In all, $60.5 \%$ perceived condoms as an effective method of contraception. The highest percentage was reported by industrial workers and drivers $(63.6 \%$ and $63.1 \%$ respectively) while the lowest percentage was that of government employees $(56.5 \%)$. Condoms were reported as an effective measure for prevention of sexually transmitted infections (STIs) by $60.0 \%$ of the respondents; drivers $(61.8 \%)$ and industrial workers $(65.8 \%)$ reported the highest percentage.

About $27 \%$ accepted the possibility of using condoms in the future with the highest percentage reported by drivers $(34.0 \%)$ and the lowest by employees $(22.2 \%)$. Regarding knowledge about the proper use of condoms $25.3 \%$ claimed to have this with the highest percentage being industrial workers (32.7\%). About 32\% thought that condom use may be associated with harmful effects and about $58 \%$ believed that the partner might possibly reject condom use. 


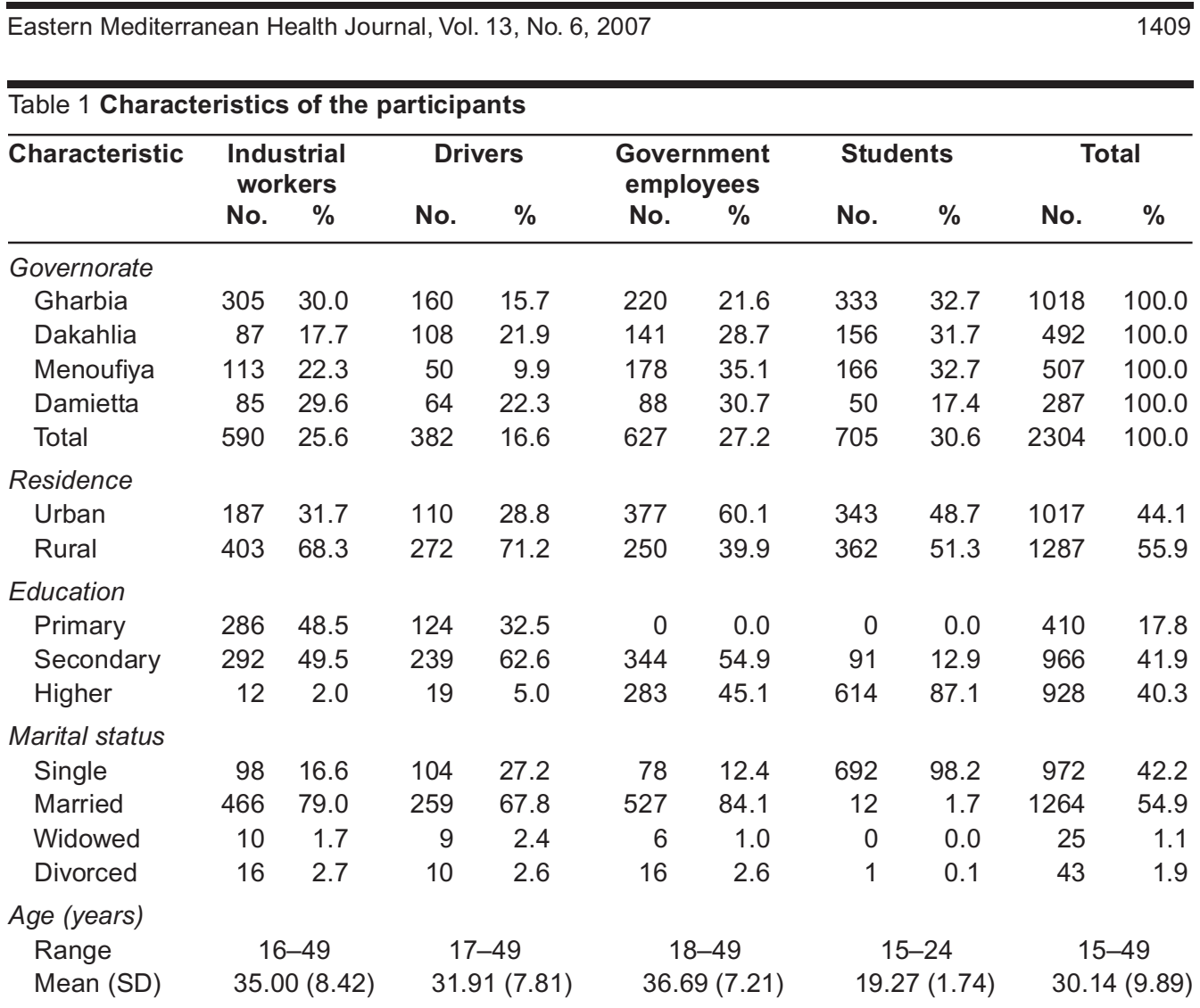

More than two-thirds of the sample (69.6\%) reported availability of condoms in their neighbourhood; $53.1 \%$ reported that they would be embarrassed to buy condoms in the presence of somebody known to them. There were statistically significant differences between the 4 groups in their attitudes and knowledge (Table 2).

Only $23.9 \%$ had ever used condoms with the highest percentage reported by industrial workers $(33.9 \%)$ and the lowest by students (10.4\%). Among single males $11.6 \%$ reported using condoms while $32.9 \%$ of married males had used condoms. Among the 552 participants who reported using condoms, the main reasons for condom use were for contraception $(56.2 \%)$ and for prevention of STIs (35.0\%); 5.6\% used them for both contraception and prevention of STIs. Only 3.3\% reported using condom during menses. The main reasons for not using condom were: no need being single or married but wanting children $(75.7 \%)$ and condoms decrease sexual pleasure $(18.3 \%)$ (Table 3). There were statistically significant differences between the groups.

The majority of the studied population reported having knowledge about HIV/ AIDS (90.8\%). Less than one-fifth reported that their behaviour put them at risk for STIs and HIV infection (11.2\% and $10.3 \%$ respectively). On the other hand, $28.9 \%$ reported having friends who engaged in extramarital sexual relations; drivers and students reported the highest percentages (33.2\% and $37.7 \%$ respectively). Differences

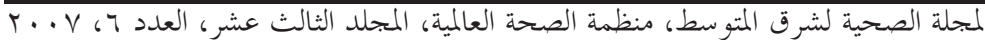




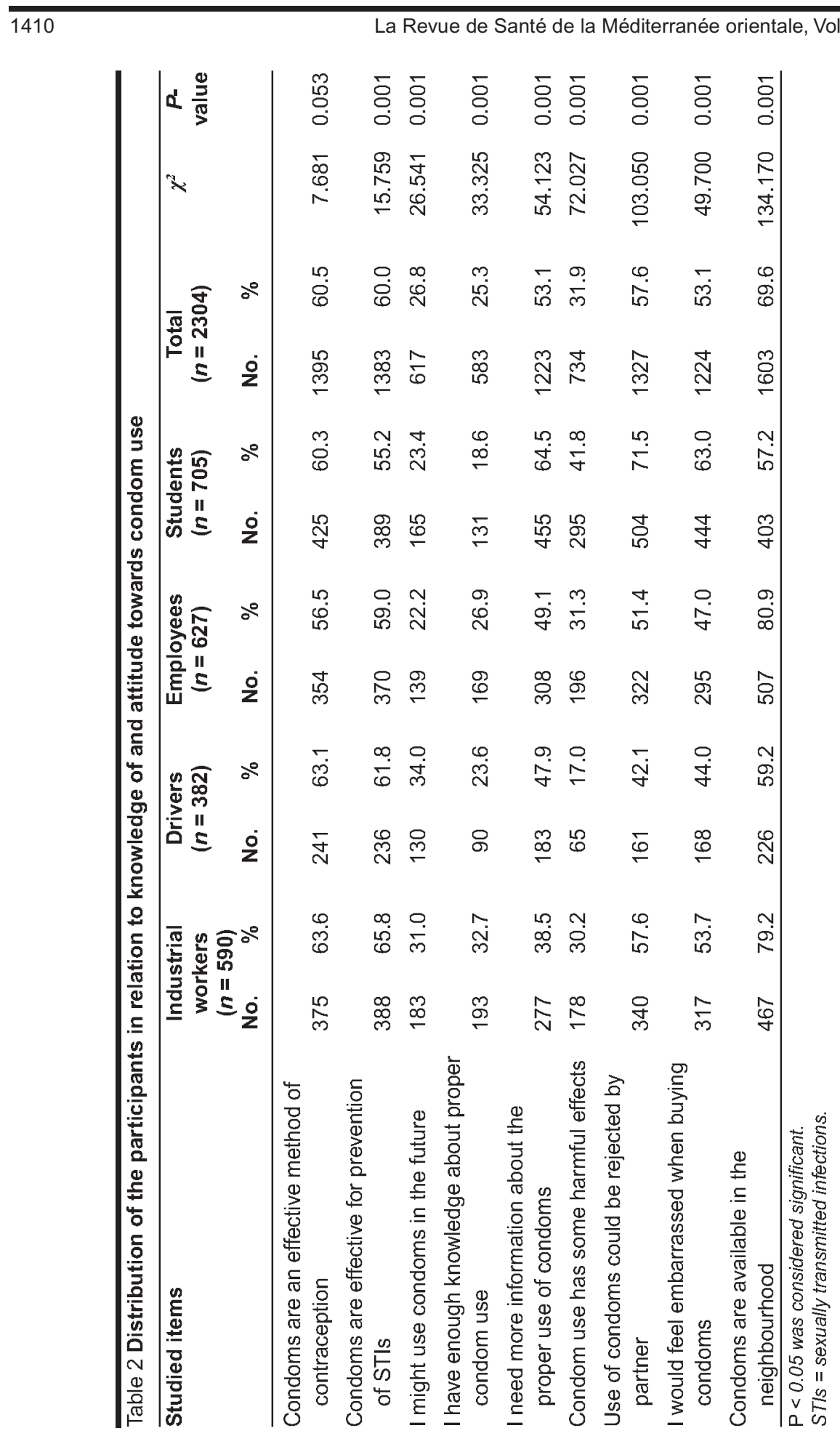

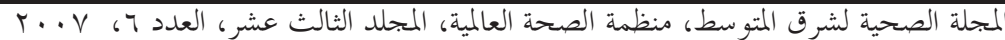




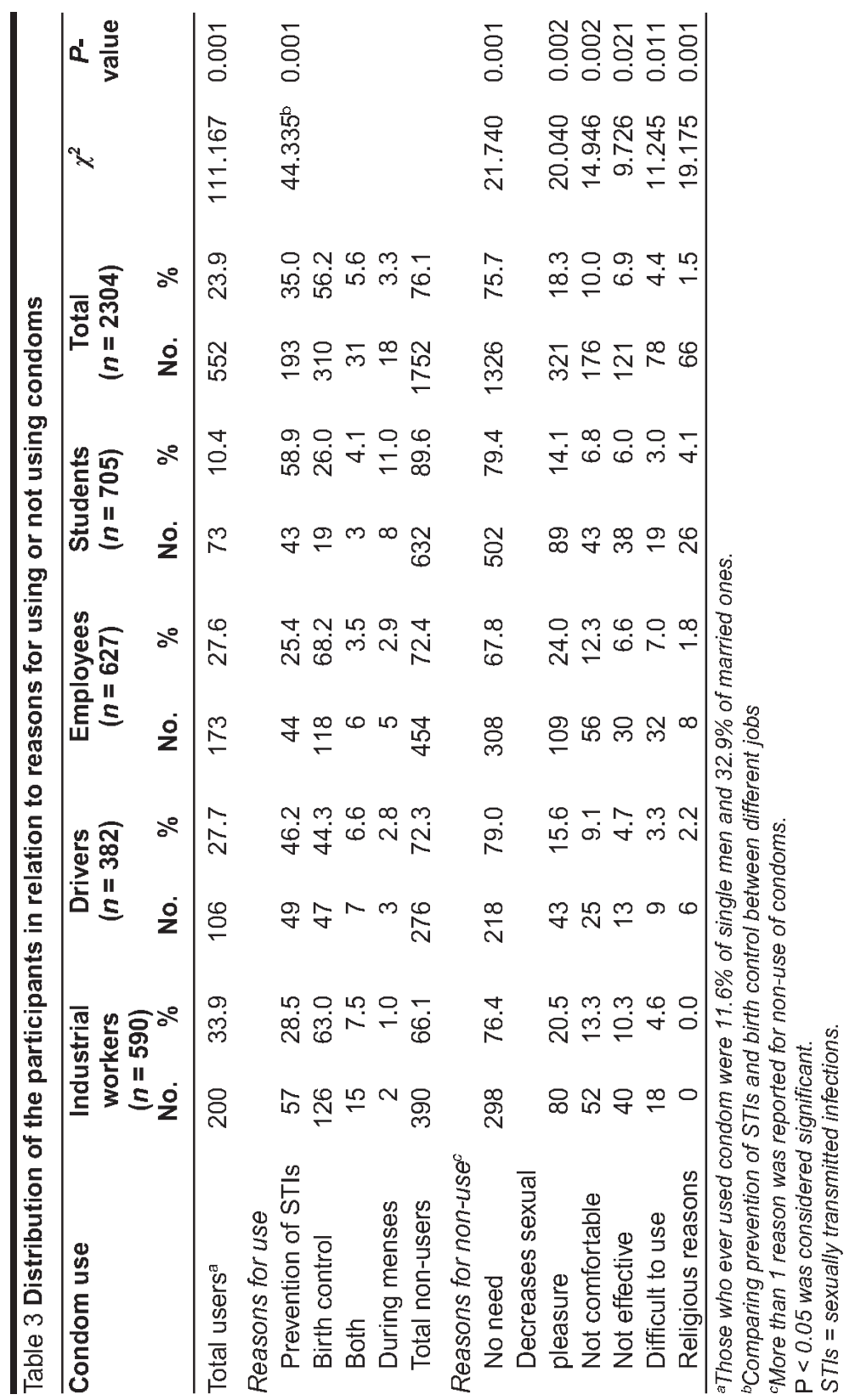

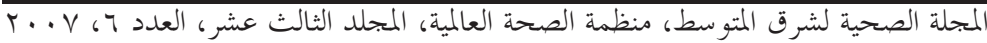


between the 4 groups were statistically significant in relation to risk perception for STIs and HIV infection and having friends engaging in extramarital sexual relations. The participants reported that these unsafe sexual relations of their friends happened frequently (44.5\%) and with multiple partners $(66.6 \%)$. Regarding condom use in the extramarital relations of their friends, $53.5 \%$ said condoms were never used while $18.4 \%$ said condoms were always used. The majority of the respondents who had friends engaged in extramarital relations (73.1\%) believed their friends were at risk for HIV/AIDS (Table 4).

\section{Discussion}

Men play a powerful and even dominant role in reproductive decisions sometimes regardless of their partner's wishes or the health consequences to themselves or their partners. For these reasons, it is important to direct the action of health programmes to healthy male sexual behaviour [13]

This study shows that slightly about $60 \%$ of the studied sample believed in the effectiveness of condom as a contraceptive method and for the prevention of STIs. Government employees had the lowest level of confidence in condoms in this regard. Properly used, male condoms are a proven and effective means of family planning and for preventing transmission of HIV/AIDS and other STIs [14]. Laboratory tests showed that no STI organism, including HIV, can pass through an intact synthetic condom. In fact, a condom protects against any STI that is transmitted through bodily fluids [15].

Many people, especially young men, may not be adequately informed about the protective effect of condoms against STIs and AIDS. In some countries, only a minority of never married men who had heard of AIDS knew that the use of condoms could prevent infection with HIV. In addition, some are too embarrassed by their lack of skills to add condom use to sexual activity [15]. Therefore, with more information and encouragement more men would be willing to use condoms [16].

Although condoms were reported by the majority of the participants in the present study to be easily available, only around a quarter had ever used condoms and or said they might be potential users in the future. Among all married persons only a third had ever used condoms. This figure is different from that reported by the Egypt Demographic and Health Survey (3.2\%) which gave the per cent of married couples using condoms only for family planning. Our study included all those in the community as a whole who had ever used condoms for any reason [2].

The low level of condom use in this study should be considered in relation to the observation that only about a quarter of the studied population reported having enough information about proper condom use and that just over half were in need of more information. The main reasons for not using condoms in the present study were: not needing it (being single or married but wanting children) and decreased sensation during sexual relations. In addition, about $30 \%$ believed that there may be harmful effects associated with condom use. Rejection by partner was another reason for non-use.

Despite the importance of condoms for protection against both pregnancy and STIs and HIV/AIDS, use of male condoms for family planning is rare, especially in developing countries [17]. While perceived unreliability is often a problem, many other issues present greater barriers to overall acceptability of condoms and may explain this wide gap between awareness and use. Insufficient knowledge about the proper method of condom use and the places to obtain 
Eastern Mediterranean Health Journal, Vol. 13, No. 6, 2007

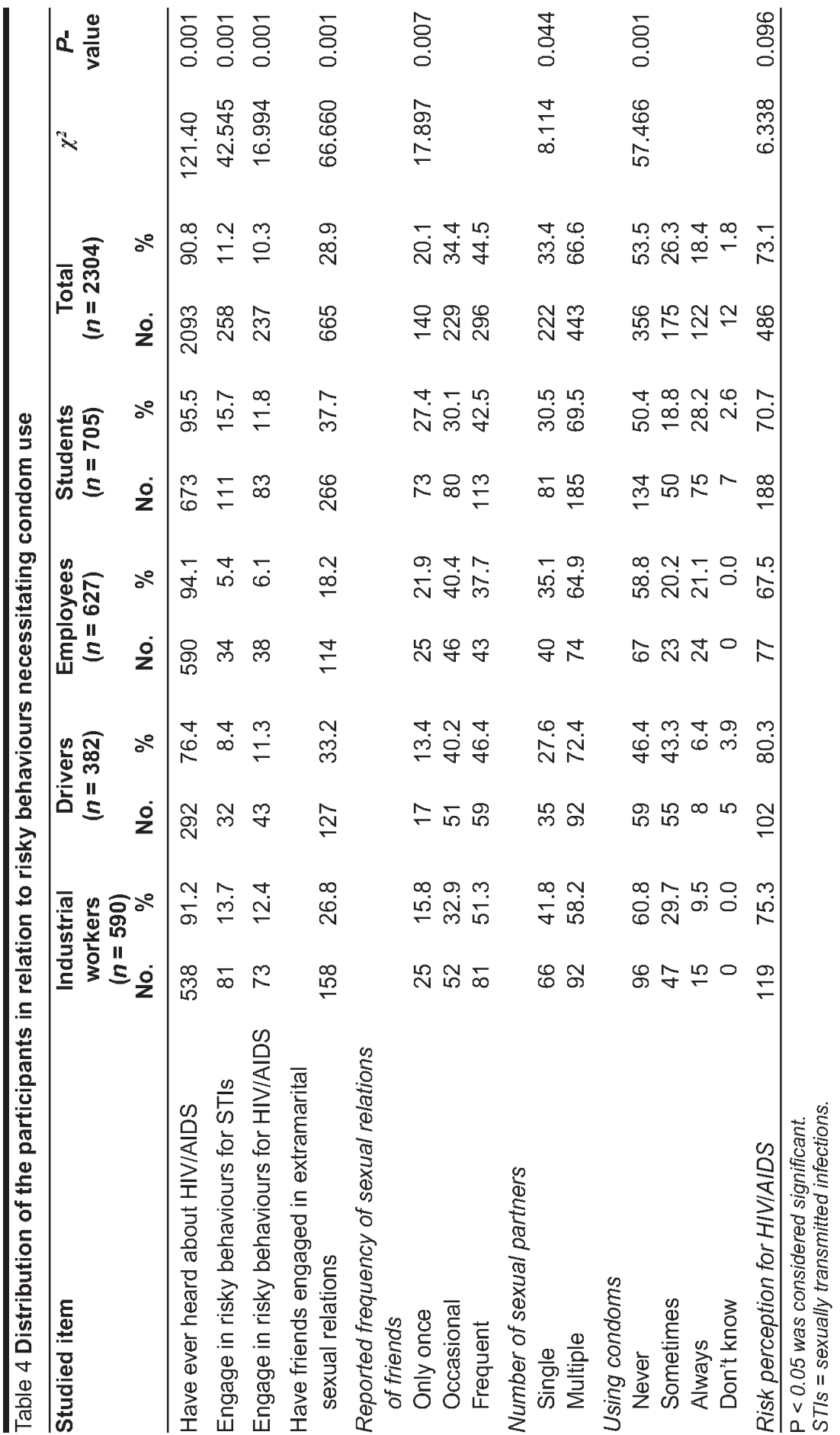

المجلة الصحية لشرق المتوسط، منظمة الصحة العالمية، المجلد الثالث عشر، العدد Y، V... 
them has also been reported to be a cause for under-utilization $[15,18]$. Among other obstacles are social disapproval that stigmatizes condom buying and use, difficulties in obtaining condoms due to restricted availability, high price, and lack of privacy at the point of sale or distribution. Fear, lack of trust in their partners, personal reluctance due to decreased sensitivity and unpleasant odour, inhibition of sexual gratification and the possible irritation of the partner's sexual organs that may interfere with intercourse are other reasons for non-use of condoms $[19,20]$. In a study among adolescents, barriers to condom use among adolescents engaged in risky behaviour were:, suddenness of the sexual event (21\%), lack of awareness of the nature of the risk and the role of condoms as a protective method $(16 \%)$, reduction in pleasure $(15 \%)$, not knowing how to use $(8 \%)$, partner is married and it is her responsibility, too shy to buy $(6 \%)$, condoms not available $(5 \%)$, partner's insistence not to use $(2 \%)$, and no response (23\%) [21]. Furthermore, many people do not believe they are at risk of STIs or AIDS and may think they do not need protection.

Among the 4 groups in our study, industrial workers and drivers were the group with the highest confidence in condom use and the highest frequency of ever use. They were also the groups that were most willing to consider using condoms in the future and were the least likely to believe that condom use has harmful effects $(30.2 \%$ and $17.0 \%$ respectively). However, fewer drivers $(59.2 \%)$ reported knowing where to obtain condoms than the other groups. These observations should be considered on trials to encourage condom use among these groups.

Sexual behaviour patterns vary widely between countries and there may be large differences in the sexual norms and prac- tices between different groups [22]. Risky sexual behaviour includes unprotected sex, irregular use of condoms, multiple partners and relationships, and particular sexual initiation rituals [23]. Risky sexual behaviour is accompanied by increased risk of contracting STIs especially HIV [24]. Despite the AIDS epidemic, and even when men know that unprotected sex is risky, many still take the risk and engage in risky sexual behaviour [15].

The majority of the sample $(90.8 \%)$ knew about HIV/AIDS. While the participants were not asked about their own sexual behaviour, their knowledge of friends engaged in extramarital relations clearly shows that unsafe, risky behaviour is present in the population. Furthermore, in spite of the low condom use observed by this study, $11.6 \%$ of single males had previous experience with condom use, suggesting they had extramarital sexual relations. Again among students, only $2.1 \%$ were married but $10.4 \%$ reported previous experience with condoms. While $73.1 \%$ of those with friends engaging in unsafe sex believed that these friends were at risk of contracting HIV/AIDS, the perception of the respondents of their own risk of STIs and HIV infection was low (11.2\% and $10.3 \%$ respectively).

\section{Conclusion and recommendations}

Condom use is still low among Egyptians. Reasons for non-use include low confidence, low perception of risk, lack of information, perceived harmful effects, decreased sensation during intercourse and social stigma of buying condoms. The presence of unsafe sexual behaviour necessitates increasing the level of condom use in Egypt through:

- Family planning, communication and social marketing campaigns to promote 
the dual role of condoms in preventing pregnancy and transmission of STIs.

- Sexual education with more information about condoms to encourage more men to play a positive role in reproductive health. Sex education for unmarried young people should stress on sexual abstinence before marriage and use of condoms for protection from STIs and HIV/AIDS.

- Voluntary counselling and testing to explore unsafe behaviours associated with STIs including HIV/AIDS, to promote condom use and to disseminate more information concerning their proper use.

- Cooperation of governmental sectors, the commercial sector and nongovern- mental organizations. This will help meet condom needs and disseminate information about condom use.

\section{Acknowledgement}

This study received technical and financial support from the joint WHO Eastern Mediterranean Regional Office (EMRO), Division of Communicable Diseases (DCD) and the WHO Special Programme for Research and Training in Tropical Diseases (TDR): The EMRO/TDR Small Grants Scheme for Operational Research in Tropical Medicine and other Communicable Diseases.

\section{References}

1. Drennan M. Reproductive health: new perspectives on men's participation. Baltimore, Johns Hopkins School of Public Health, Population Information Program, 1998 (Population Reports, Series J, No. 46).

2. Lewis $\mathrm{JH}$. Why a monograph of latex condom. In: McNeil ET, et al., eds. The latex condom: recent advances, future directions. Research Triangle Park NC, Family Health International, 1997:2.

3. Trussell J. Contraceptive efficacy. In: Hatcher RA et al., eds. Contraceptive technology, 17th ed. New York, Irvington Publishers Incorporated, 1999.

4. Cates W Jr, Stone KM, Family planning, sexually transmitted diseases and contraceptive choice: a literature update. Part I. Family planning perspectives, 1992, 24:75-84.

5. Daly CC et al. Contraceptive methods and the transmission of HIV: implications for family planning. Genitourinary medicine, 1994, 70:110-7.
6. De Vincenzi I. The European Study Group on Heterosexual Transmission of HIV. A longitudinal study of human immunodeficiency virus transmission by heterosexual partners. New England journal of medicine, 1994, 331:341-6.

7. El Zanaty A, Way A. Egypt Demographic and Health Survey, 2003. Cairo, Ministry of Health and Population, National PopuIation Council; Calverton, Maryland, ORC Macro, 2003.

8. Roudi F, Ashford LS. Men and family planning: focus on Egypt. Population today, 1996, 24(2):3.

9. El Salamouny OK, EI Raghi HA, El Lawindi MI. Male role in reproductive health: Assessment of some perceptions and behaviors among husbands and wives. Egyptian journal of community medicine, 2004, 22(1):1-11.

10. Fikree F, Saleem S, Sami N. A quality of care issue: appropriate use and efficacy knowledge of five contraceptive methods:

المجلة الصحية لشرق المتو سط، منظمة الصحة العالمية، المجلد الثالث عشر، العدد Y، V... 
views of men and women living in low socioeconomic settlements of Karachi, Pakistan. Journal of the Pakistan Medical Association, 2005, 55(9):363-8.

11. Spruyt $A B$, Finger WR. Acceptability of condoms: user behavior and product attributes. In: McNeill ET et al., eds The latex condom: recent advances, future directions. Research Triangle Park NC, Family Health International, 1997:13.

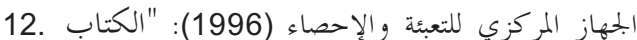

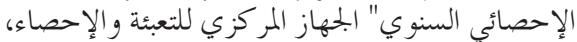
[Annual statistics book. Cairo, Cental Agency for Population Management and Statistics, 1996].

13. Lasee A, Becker S. Husband-wife communication about family planning and contraceptive use in Kenya. International family planning perspectives, 1997. 23(1):15-20.

14. The male condom. UNAIDS Technical update. Geneva, UNAIDS, 2000 (A Best Practice Collection) (http://data.unaids. org/Publications/IRC-pub01/JC302TU18-MaleCondom_en.pdf, accessed 15 May 2007).

15. Gardner R, Blackburn RD, Upadhyay UD. Closing the condom gap. Baltimore, Johns Hopkins School of Public Health, Population Information Program, 1999 (Population Reports, Series H, No. 9).

16. Ushma D, Upadhyay MPH, Bryant Robey MA. Why family planning matters. Baltimore, Johns Hopkins School of Public Health, Population Information Program, 1999 (Population Reports, Series J, No. 49).

17. Zlidar VM et al. New survey findings: the reproductive revolution continues. Bal- timore, Johns Hopkins School of Public Health, the INFO Project, 2003 (Population Reports, Series M, No. 17).

18. Curtis SL, Neitzel K. Contraceptive knowledge, use, and sources. Calverton, Maryland, Macro International, 1996 (Demographic and Health Surveys Comparative Studies No. 19).

19. The impact of voluntary counseling and testing. A global review of the benefits and challenges. UNAIDS Report. 2000. Geneva, Joint United Nations Programme on HIVIAIDS, 2000.

20. The condom situation assessment in 11 Asian and Western Pacific Countries. New Delhi, WHO Regional Office for South-East Asia; Manila, WHO Regional Office for the Western Pacific, 2001.

21. Abraham L. Risk behaviour and misperceptions among low-income college students of Mumbai. In: Bott S et al., eds. Towards adulthood:exploring the sexual and reproductive health of adolescents in South Asia. Geneva, World Health Organization, 2003:73-7.

22. Carael M. Sexual behavior. In: Cleland J, Ferry B, eds. Sexual behavior and AIDS in the developing world. Geneva, World Health Organization, 1995:75-123.

23. Rapid assessment and response. Technical guide (TGRAR). Geneva, World Health Organization, 2003 (http://www. who.int/docstore/hiv/Core/Index.html, accessed 15 May 2007).

24. Over M, Piot P. HIV infection and sexually transmitted diseases. In: Jamison DT et al., eds. Disease control priorities in developing countries. New York, Oxford University Press, 1992:455-527. 